\title{
Water-to-Water Turbulent Flow Heat Exchanger Performance Analysis
}

\author{
Kerim Martin \\ Gazi University/Institute of Science and Technology/Energy Systems Engineering
}

\begin{abstract}
Energy efficiency is one of the most studied topics. Nearly half of the energy generated worldwide is consumed in industry. Therefore, energy efficiency applications in the industrial area are of greater importance. In addition, efficient use of energy will reduce $\mathrm{CO}_{2}$ emissions and have a positive impact on the environment. Waste heat recovery units have an important place in the industry in terms of energy efficiency. In this study, experimentally, the performance analysis of the double pipe water-to-water heat exchanger was performed and the data obtained were compared with the CFD analysis. In the study, hot fluid flow rates are 50 and $100 \mathrm{~g} / \mathrm{s}$, while cold fluid flow rates are 10, 20 and $30 \mathrm{~g} / \mathrm{s}$. The experiments were performed separately in the parallel and counter flow types. LMTD (Logarithmic Mean Temperature Difference) values were calculated for both flow types. When the average heat transfer area and coefficient of the heat exchanger for the parallel and counter flow types were considered equal, it was found that the counter flow was more effective when compared with LMTD values. In addition, $89.1 \%$ of the energy of the hot fluid was transferred to the cold fluid in the counter flow while this value was $87.8 \%$ in the parallel flow. CFD analysis was performed for the same conditions and results were very close to the experimental study.
\end{abstract}

Keywords: CFD; Energy Efficiency; Heat Recovery; Heat Transfer; LMTD 